\title{
TEOREMA INVERSI PADA FUNGSI KARAKTERISTIK
}

\author{
TIKA YULIANA \\ Program Studi Matematika, \\ Fakultas Matematika dan Ilmu Pengetahuan Alam, Universitas Andalas Padang, \\ Kampus UNAND Limau Manis Padang, Indonesia \\ yulianatika09@yahoo.co.id
}

\begin{abstract}
Abstrak. Fungsi karakteristik dari suatu peubah acak $X$ dinotasikan sebagai $\varphi_{X}(t)$ dan didefinisikan sebagai $\varphi_{X}(t)=E\left[e^{i t X}\right]$, dimana $t \in \mathbb{R}, i=\sqrt{-1}$ dan $e^{i t X}=\cos t X+$ $i \sin t X$. Teorema inversi menyatakan bahwa fungsi karakteristik dapat digunakan untuk menentukan fungsi kepekatan peluang dari peubah acak yaitu
\end{abstract}

$$
f(x)=\frac{1}{2 \pi} \int_{-\infty}^{\infty} e^{-i t x} \varphi_{X}(t) d t .
$$

Kata Kunci: Fungsi karakteristik, teorema inversi, peubah acak.

\section{Pendahuluan}

Pada teori peluang dan statistika digunakan beberapa transformasi dan fungsi pembangkit, salah satunya fungsi karakteristik. Lukacs (1960) menyatakan bahwa fungsi karakteristik dari suatu peubah acak $X$ dinotasikan sebagai $\varphi_{X}(t)$ dan didefinisikan sebagai

$$
\varphi_{X}(t)=E\left[e^{i t X}\right]
$$

dimana $e^{i t X}=\cos (X)+i \sin (X)$. Jelas terlihat bahwa fungsi karakteristik mempunyai kesamaan dengan fungsi pembangkit momen $M_{X}(t)=E\left[e^{t X}\right]$ (lihat Bain dan Engelhardt (1992)), akan tetapi dengan menambahkan ' $i$ ' pada eksponennya, dimana $i$ adalah bilangan imajiner.

Sama halnya dengan fungsi pembangkit momen, fungsi karakteristik juga dapat digunakan untuk menghitung momen dari suatu peubah acak. Selain itu, fungsi karakteristik juga dapat digunakan untuk menentukan fungsi distribusi dari suatu peubah acak. Berbeda dengan fungsi pembangkit lainnya, fungsi karakteristik selalu ada untuk setiap fungsi distribusi, karena

$$
\left|\varphi_{X}(t)\right|=\left|E\left[e^{i t X}\right]\right| \leq E\left[\left|e^{i t X}\right|\right]=E[1]<\infty .
$$

Rao dan Swift (2006) menyatakan bahwa fungsi karakteristik secara tunggal menentukan sebaran peluang yang bersesuaian dengan peubah acaknya. Jadi setiap sebaran peluang memiliki fungsi karakteristik yang berbeda. Ketunggalan fungsi karakteristik merupakan akibat dari teorema inversi fungsi karakteristik, dimana secara eksplisit teorema inversi dapat menentukan fungsi distribusi $F(x)$ bilamana fungsi karakteristik $\varphi_{X}(t)$ diketahui. Oleh sebab itu, kajian tentang teorema inversi 
pada fungsi karakteristik sangat menarik untuk dikaji. Jadi dalam makalah ini akan dibahas pembuktian teorema inversi pada fungsi karakteristik.

Makalah ini merupakan tinjauan ulang dari rujukan pustaka [3]. Pada makalah ini penulis mengkaji kembali tentang teorema inversi pada fungsi karakteristik.

\section{Teorema Inversi Pada Fungsi Karakteristik}

Teorema 2.1. Jika $F$ terdiferensial pada $x$ dengan $F^{\prime}(x)=f(x)$ maka

$$
f(x)=\lim _{h \rightarrow 0} \lim _{T \rightarrow \infty} \frac{1}{2 \pi} \int_{-T}^{T} \frac{1-e^{-i h t}}{i h t} e^{-i t x} \varphi_{X}(t) d t
$$

jika dan hanya jika ruas kanan dari persamaan (1) ada. Jika $\varphi_{X}(t)$ terintegral pada $\mathbb{R}$ dan $f(x)$ ada untuk setiap $x \in \mathbb{R}$ maka

$$
f(x)=\frac{1}{2 \pi} \int_{-\infty}^{\infty} e^{-i t x} \varphi_{X}(t) d t .
$$

Bukti. $(\Rightarrow)$ Perhatikan persamaan (1) yaitu

$$
\begin{aligned}
f(x) & =\lim _{h \rightarrow 0} \lim _{T \rightarrow \infty} \frac{1}{2 \pi} \int_{-T}^{T}\left(\frac{1-e^{-i h t}}{i h t}\right) e^{-i t x} \varphi_{X}(t) d t . \\
& =\lim _{h \rightarrow 0} \frac{1}{h} \lim _{T \rightarrow \infty} \frac{1}{2 \pi} \int_{-T}^{T} \frac{e^{-i t x}-e^{-i(x+h) t}}{i t} \varphi_{X}(t) d t .
\end{aligned}
$$

Akibatnya, dapat dituliskan bahwa

$$
\begin{aligned}
F(x+h)-F(x) & =\lim _{T \rightarrow \infty} \frac{1}{2 \pi} \int_{-T}^{T}\left(\frac{e^{-i t x}-e^{-i(x+h) t}}{i t}\right) \varphi_{X}(t) d t \\
& =\lim _{T \rightarrow \infty} \frac{1}{2 \pi} \int_{-T}^{T}\left(\frac{1-e^{-i h t}}{i t}\right) e^{-i t x} \varphi_{X}(t) d t
\end{aligned}
$$

atau

$$
\frac{F(x+h)-F(x)}{h}=\lim _{T \rightarrow \infty} \frac{1}{2 \pi} \int_{-T}^{T}\left(\frac{1-e^{-i h t}}{i h t}\right) e^{-i t x} \varphi_{X}(t) d t .
$$

Ini berarti persamaan (1) dapat dituliskan menjadi

$$
f(x)=\lim _{h \rightarrow 0} \frac{1}{h}(F(x+h)-F(x)) .
$$

Karena $F$ terdiferensial di $x$, maka

$$
f(x)=\lim _{h \rightarrow 0} \frac{F(x+h)-F(x)}{h}=F^{\prime}(x) .
$$

Dengan perkataan lain, ruas kanan persamaan (1) ada.

$(\Leftarrow)$ Dari persamaan $(2)$ dapat dilihat bahwa ruas kanan persamaan (1) adalah sebagai berikut,

$$
\lim _{h \rightarrow 0} \lim _{T \rightarrow \infty} \frac{1}{2 \pi} \int_{-T}^{T}\left(\frac{1-e^{-i h t}}{i h t}\right) e^{-i t x} \varphi_{X}(t) d t=\lim _{h \rightarrow 0} \frac{F(x+h)-F(x)}{h}=F^{\prime}(x) .
$$


Karena $F^{\prime}(x)=f(x)$, jadi

$$
f(x)=\lim _{h \rightarrow 0} \lim _{T \rightarrow \infty} \frac{1}{2 \pi} \int_{-T}^{T}\left(\frac{1-e^{-i h t}}{i h t}\right) e^{-i t x} \varphi_{X}(t) d t .
$$

Selanjutnya karena $f(x)$ ada untuk setiap $x \in \mathbb{R}$, maka dari persamaan (1) diperoleh

$$
\begin{aligned}
f(x) & =\lim _{h \rightarrow 0} \lim _{T \rightarrow \infty} \frac{1}{2 \pi} \int_{-T}^{T}\left(\frac{1-e^{-i h t}}{i h t}\right) e^{-i t x} \varphi_{X}(t) d t \\
& =\frac{1}{2 \pi} \int_{-\infty}^{\infty}\left(\lim _{h \rightarrow 0} \frac{1-e^{-i h t}}{i h t}\right) e^{-i t x} \varphi_{X}(t) d t .
\end{aligned}
$$

Karena

$$
\lim _{h \rightarrow 0} \frac{1-e^{-i h t}}{i h t}=\lim _{h \rightarrow 0} \frac{1-\cos (-t h)-i \sin (-t h)}{i h t}=1,
$$

maka

$$
f(x)=\frac{1}{2 \pi} \int_{-\infty}^{\infty} e^{-i t x} \varphi_{X}(t) d t
$$

Contoh 2.2. Misalkan $X \sim \operatorname{Cauchy}(0,1)$ memiliki fungsi karakteristik $e^{-|t|}$ (lihat Rao dan Swift (2006)). Dengan teorema inversi dapat dicari fungsi kepekatan peluang dari sebaran Cauchy tersebut. Perhatikan bahwa

$$
\begin{aligned}
f(x) & =\frac{1}{2 \pi} \int_{-\infty}^{\infty} e^{-i t x} \varphi_{X}(t) d t \\
& =\frac{1}{2 \pi} \int_{-\infty}^{\infty} e^{-i t x} e^{-|t|} d t \\
& =\frac{1}{2 \pi} \int_{-\infty}^{\infty}[\cos (t x)-i \sin (t x)] e^{-|t|} d t
\end{aligned}
$$

karena $\cos (t x)$ adalah fungsi genap dan $\sin (t x)$ adalah fungsi ganjil, maka $f(x)$ dapat dituliskan kembali dalam bentuk sebagai berikut

$$
\begin{aligned}
f(x) & =\frac{1}{\pi} \int_{0}^{\infty} \cos (t x) e^{-|t|} d t \\
& =\frac{1}{\pi} \int_{0}^{\infty} \cos (t x) e^{-t} d t .
\end{aligned}
$$

dengan

$$
\begin{aligned}
\int_{0}^{\infty} \cos (t x) e^{-t} d t & =\lim _{a \rightarrow \infty}\left[e^{-t} \frac{1}{x} \sin (t x)\right]_{0}^{a}+\int_{0}^{\infty} \frac{1}{x} \sin (t x) e^{-t} d t \\
& =\lim _{a \rightarrow \infty}\left[e^{-t} \frac{1}{x} \sin (t x)\right]_{0}^{a}+\frac{1}{x}\left[e^{-t}\left(-\frac{1}{x} \cos (t x)\right)-\frac{1}{x} \int_{0}^{\infty} \cos (t x) e^{-t} d t\right] \\
& =\lim _{a \rightarrow \infty}\left[\frac{e^{-t}}{x} \sin (t x)-\frac{e^{-t}}{x^{2}} \cos (t x)\right]_{0}^{a}-\frac{1}{x^{2}} \int_{0}^{\infty} \cos (t x) e^{-t} d t
\end{aligned}
$$


Sehingga dapat diperoleh

$$
\begin{aligned}
\left(1+\frac{1}{x^{2}}\right) \int_{0}^{\infty} \cos (t x) e^{-t} d t & =\lim _{a \rightarrow \infty}\left[\frac{e^{-t}}{x} \sin (t x)-\frac{e^{-t}}{x^{2}} \cos (t x)\right]_{0}^{a} \\
\left(\frac{x^{2}+1}{x^{2}}\right) \int_{0}^{\infty} \cos (t x) e^{-t} d t & =\lim _{a \rightarrow \infty}\left[\frac{e^{-t}}{x} \sin (t x)-\frac{e^{-t}}{x^{2}} \cos (t x)\right]_{0}^{a} \\
\int_{0}^{\infty} \cos (t x) e^{-t} d t & =\lim _{a \rightarrow \infty}\left[\frac{e^{-t}}{x} \sin (t x)-\frac{e^{-t}}{x^{2}} \cos (t x)\right]_{0}^{a} \frac{x^{2}}{x^{2}+1} \\
& =\frac{1}{1+x^{2}}
\end{aligned}
$$

Jadi,

$$
\begin{aligned}
f(x) & =\frac{1}{\pi} \int_{0}^{\infty} \cos (t x) e^{-t} d t \\
& =\frac{1}{\pi} \frac{1}{1+x^{2}} .
\end{aligned}
$$

\section{Ucapan Terima kasih}

Penulis mengucapkan terima kasih kepada Bapak Dodi Devianto, Bapak Admi Nazra, Ibu Hazmira Yozza, Ibu Lyra Yulianti dan Bapak Budi Rudianto yang telah memberikan masukan dan saran sehingga makalah ini dapat diselesaikan dengan baik.

\section{Daftar Pustaka}

[1] Bain, L.J. dan M. Engelhardt. 1992. Introduction to Probability and Mathematical Statistics Second Edition. Duxbury Press, California.

[2] Lukacs, E. 1960. Characteristic Functions. Charles Griffin dan Company Limited, London.

[3] Maspupu, J. 2008. Peranan Formulasi Inversi pada Fungsi Karakteristik suatu Variabel Acak. Prosiding Seminar Nasional Sains dan Teknologi-II 2008 Universitas Lampung, 17-18 November 2008. 216-221.

[4] Rao, M.M. dan R.J. Swift. 2006. Probability with Applications Second Edition. Springer, United States of America. 